\title{
Antimicrobial susceptibility and genetic similarity of ESBL-positive Klebsiella pneumoniae strains
}

Alicja Sękowska, Eugenia Gospodarek, Dorota Kamińska

Department of Microbiology, Nicolaus Copernicus University, Collegium Medicum, Bydgoszcz, Poland

Submitted: 10 July 2011

Accepted: 25 November 2011

Arch Med Sci 2012; 8, 6: 993-997

DOI: 10.5114/aoms.2012.32404

Copyright $\odot 2012$ Termedia \& Banach

\author{
Corresponding author: \\ Alicja Sękowska PhD \\ Department of Microbiology \\ Nicolaus Copernicus University \\ Collegium Medicum \\ 9 M. Skłodowskiej-Curie St \\ 85-094 Bydgoszcz, Poland \\ Phone: +48525853501 \\ E-mail: ala.sek@wp.pl
}

\begin{abstract}
Introduction: Twenty-eight isolates of extended-spectrum $\beta$-lactamase (ESBL)positive Klebsiella pneumoniae were studied.

Material and methods: The strains were cultured from different clinical specimens obtained from children hospitalised at the University Hospital in Bydgoszcz. Seventeen strains were isolated from colonization and eleven from clinical infection. Isolation and identification of bacteria were performed using routine methods at the clinical microbiology laboratory. Production of ESBL was assessed using the double disk synergy test. The susceptibility to imipenem and tigecycline was tested by the Etest. The susceptibility to gentamicin and ciprofloxacin was tested by the agar dilution method. The genomic DNA was extracted from the strains separated by pulsed-field gel electrophoresis (PFGE) after digesting with $\mathrm{Xbal}$ endonuclease.

Results: Among analysed K. pneumoniae strains all were susceptible to imipenem, $21(75.0 \%)$ were susceptible to tigecycline, 14 (50.0\%) to gentamicin and $5(17.9 \%)$ to ciprofloxacin. Molecular typing results revealed a great genetic diversity among K. pneumoniae isolates. All repeated PFGE patterns were detected in seven K. pneumoniae isolates. Among identical K. pneumoniae strains four susceptibility patterns were detected.

Conclusions: The results of the study suggest that establishing strains' similarity in epidemiological investigations should be based on results obtained by several methods, and that each phenotyping method should be complemented with genetic research.
\end{abstract}

Key words: Klebsiella pneumoniae, ESBL phenotype, susceptibility to antibiotics, pulsed-field gel electrophoresis.

\section{Introduction}

Klebsiella pneumoniae rods are one of the most important bacteria which cause nosocomial infections, especially at paediatric units. $\beta$-Lactamases are the most frequent source of resistance to $\beta$-lactam antibiotics. Different $\beta$-lactamases are known: penicillinases, extended-spectrum $\beta$-lactamases (ESBL), cephalosporinases (AmpC), metallo- $\beta$-lactamases $(\mathrm{MBL})$ and carbapenemases (KPC). Each of them can be produced by Klebsiella strains. Klebsiella pneumoniae are one of the most frequent ESBL producers, including in Poland [1-3]. Strains with this phenotype hydrolyse penicillins and some cephalosporins, and are normally not inhibited by $\beta$-lactamase inhibitors. ESBL-positive strains are often resistant to non$\beta$-lactam antibiotics, so treatment of these infections appears to be very 
difficult because of the strains' multidrug resistance. Since ESBL-producing strains were first recognized, their emergence and rapid dissemination have been responsible for numerous outbreaks of infection throughout the world [4-6]. Strains with this phenotype generally remain susceptible to only a few antimicrobial agents, some of which are not always recommended for use in children.

Phenotypic methods such as biotyping and serotyping have been providing the mainstay in descriptive epidemiology of bacteria. Genetic methods allow one to evaluate the relatedness of strains and the epidemiological situation in a hospital. Pulsed-field gel electrophoresis (PFGE) is a genetic typing method that is widely used as a molecular epidemiological tool for studying the genetic diversity of $K$. pneumoniae $[7,8]$.

The purpose of this dissertation was to evaluate antimicrobial susceptibility and genetic similarity of ESBL-positive K. pneumoniae strains isolated from colonization and infections from children hospitalised at the Paediatric Surgery Unit at the Dr Jurasz University Hospital in Bydgoszcz in a period of 15 months.

\section{Material and methods}

The study included 28 K. pneumoniae strains isolated from 18 children. Isolation and identification of bacteria were performed using routine methods at the clinical microbiology laboratory. The isolates were identified with commercial ID32E tests (bioMérieux). The antimicrobial susceptibility tests for gentamicin and ciprofloxacin were performed by the agar dilution method. Minimal inhibitory concentration (MIC) for imipenem and tigecycline was determined by the Etest (AB Biodisk). Susceptibility breakpoints for antibiotics were established according to the recommendations of the European Committee on Antimicrobial Susceptibility Testing [9]. Escherichia coli ATCC 25922 and K. pneumoniae ATCC 700603 were used as reference strains. For every strain the ESBL producing ability was deter- mined by means of two disks and the EUCAST method.

Genetic relatedness was assessed by PFGE using $X$ bal enzyme. Electrophoresis conditions were as follows: $14^{\circ} \mathrm{C}$ at $6 \mathrm{~V} / \mathrm{cm}$ for $20 \mathrm{~h}$ with pulse time ranging from $2 \mathrm{~s}$ to $35 \mathrm{~s}$. As a reference chromosomal DNA pattern Lambda Ladder standard (Bio-Rad) was used. Results were interpreted according to Tenover et al. [10] and Molecular Analyst Fingerprinting (MAF, Bio-Rad).

\section{Results}

Seventeen K. pneumoniae (60.7\%) strains were isolated from colonization. These strains were cultured from: throat swabs - $9(32.2 \%)$, rectal swabs - 6 (21.4\%) and stool samples - 2 (7.1\%). Eleven (39.3\%) strains were isolated from children with clinical symptoms of infection from: blood $6(21.4 \%)$, urine $-3(10.8 \%)$ and cerebrospinal fluid samples -2 (7.1\%). All the K. pneumoniae strains in this study demonstrated ESBL-mediated resistance and most of them were resistant to ciprofloxacin.

Among the analysed strains all of them were susceptible to imipenem, 21 (75.0\%) to tigecycline, $14(50.0 \%)$ to gentamicin and 5 (17.9\%) to ciprofloxacin. Four K. pneumoniae strains were intermediate to tigecycline. The results of antimicrobial susceptibility testing are presented in Table I. Imipenem MICs were 0.19-1 mg/l. Tigecycline MICs varied from $0.25 \mathrm{mg} / \mathrm{l}$ to $8 \mathrm{mg} / \mathrm{l}$. Gentamicin and ciprofloxacin MICs were $0.125-256 \mathrm{mg} / \mathrm{l}$.

Against the analysed K. pneumoniae strains, imipenem revealed the highest activity, with $\mathrm{MIC}_{50 \mathrm{~S}}$ $0.19 \mathrm{mg} / \mathrm{l}$ and $\mathrm{MIC}_{90 \mathrm{~S}} 0.38 \mathrm{mg} / \mathrm{l}$. Against the analysed K. pneumoniae strains, ciprofloxacin showed the lowest activity, with $\mathrm{MIC}_{50 \mathrm{~s}} 2 \mathrm{mg} / \mathrm{l}$ and $\mathrm{MIC}_{90 \mathrm{~s}} 16 \mathrm{mg} / \mathrm{l}$.

According to the PFGE testing results, the study strains were divided into four subgroups: 7 (25.0\%) identical strains (group A - lines 9, 10, 10*, 12, 12*, $\left.13,13^{\star}\right) ; 9(32.2 \%)$ closely related strains (group B lines $\left.2,8,8^{\star}, 9^{\star}, 11,11^{\star}, 14^{\star}, 16,16^{\star}\right) ; 4(14.2 \%)$ possibly related strains (group C - lines $1,5,7,7^{\star}$ ); and

Table I. Antimicrobial susceptibility of K. pneumoniae ESBL-positive strains $(n=28)$

\begin{tabular}{|c|c|c|c|c|c|}
\hline \multicolumn{4}{|c|}{ Antibiotics } & \multirow{2}{*}{$\begin{array}{c}\text { Susceptibility } \\
\text { pattern }\end{array}$} & \multirow{2}{*}{$\begin{array}{l}\text { Number } \\
\text { of strains }\end{array}$} \\
\hline Imipenem & Gentamicin & Tigecycline & Ciprofloxacin & & \\
\hline S & $\mathrm{S}$ & $\mathrm{S}$ & $\mathrm{S}$ & $\mathrm{a}$ & 2 \\
\hline $\mathrm{S}$ & $\mathrm{R}$ & $\mathrm{S}$ & $\mathrm{S}$ & $b$ & 2 \\
\hline$S$ & $\mathrm{~S}$ & $\mathrm{R}$ & $\mathrm{S}$ & c & 1 \\
\hline $\mathrm{S}$ & $\mathrm{S}$ & $\mathrm{S}$ & $\mathrm{R}$ & $\mathrm{d}$ & 9 \\
\hline$S$ & $\mathrm{~S}$ & $\mathrm{R}$ & $\mathrm{R}$ & e & 2 \\
\hline $\mathrm{S}$ & $R$ & 1 & $\mathrm{R}$ & f & 4 \\
\hline$S$ & $\mathrm{R}$ & $\mathrm{S}$ & $\mathrm{R}$ & g & 8 \\
\hline
\end{tabular}

$S$ - susceptible, 1 - intermediate, $R$ - resistant 


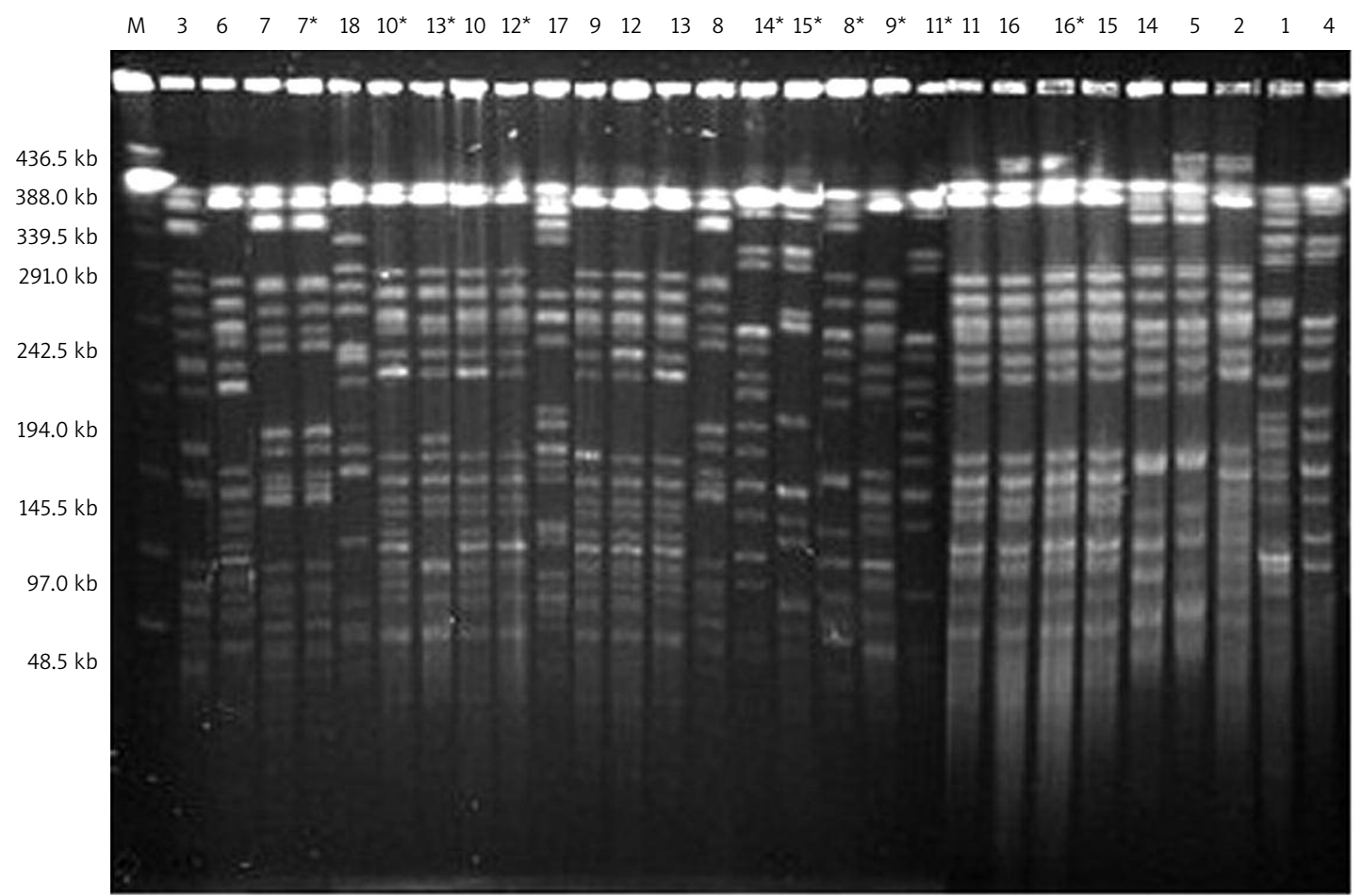

Figure 1. PFGE fingerprinting of Xbal -digested DNA from $K$. pneumoniae ESBL-positive strains $(n=28)$

$M$ - Lamba Ladder stander, 1-16 strain number, strains marked *were isolated from infections

$8(28.6 \%)$ unrelated strains (group D - lines 3, 4, 6, $\left.14,15,15^{\star}, 17,18\right)$. The results of PFGE and MAF are presented in Figures 1 and 2. Among K. pneumoniae strains, which were isolated from colonization, 3 identical, 5 closely related, 2 possibly related and 7 different strains were detected according to Tenover et al. [10]. Among K. pneumoniae strains which were cultured from infections, 4 identical, 4 closely related, 2 possibly related and 1 different strains were detected according to Tenover [10]. Six strains showed $95 \%$ similarity according to MAF.

Among identical $K$. pneumoniae strains four susceptibility patterns were noted (b, d, e, g). All identical strains were susceptible to imipenem. Among closely related strains four susceptibility patterns ( $d, e, f, g$ ) were detected. These strains were susceptible to imipenem and resistant to ciprofloxacin. Among possibly related strains two susceptibility patterns were detected $(\mathrm{a}, \mathrm{g})$. These strains were susceptible to imipenem and tigecycline. Among different $K$. pneumoniae strains three susceptibility patterns were detected (c, d, f). All of these strains were susceptible to imipenem.

The K. pneumoniae strains that were isolated from the same child from colonization and infection had the same susceptibility pattern (Table II). Among the analysed strains " $d$ " and "g" susceptibility patterns dominated. These patterns were detected in $9(32.1 \%)$ and 8 (28.6\%) strains, respectively. The $K$. pneumoniae strains cultured from the same child from colonization and infection belonged to the same genetic group in 8 cases.

\section{Discussion}

Klebsiella pneumoniae bacilli can be typed by means of various methods. The commonly applied typing methods rely on biochemical properties,

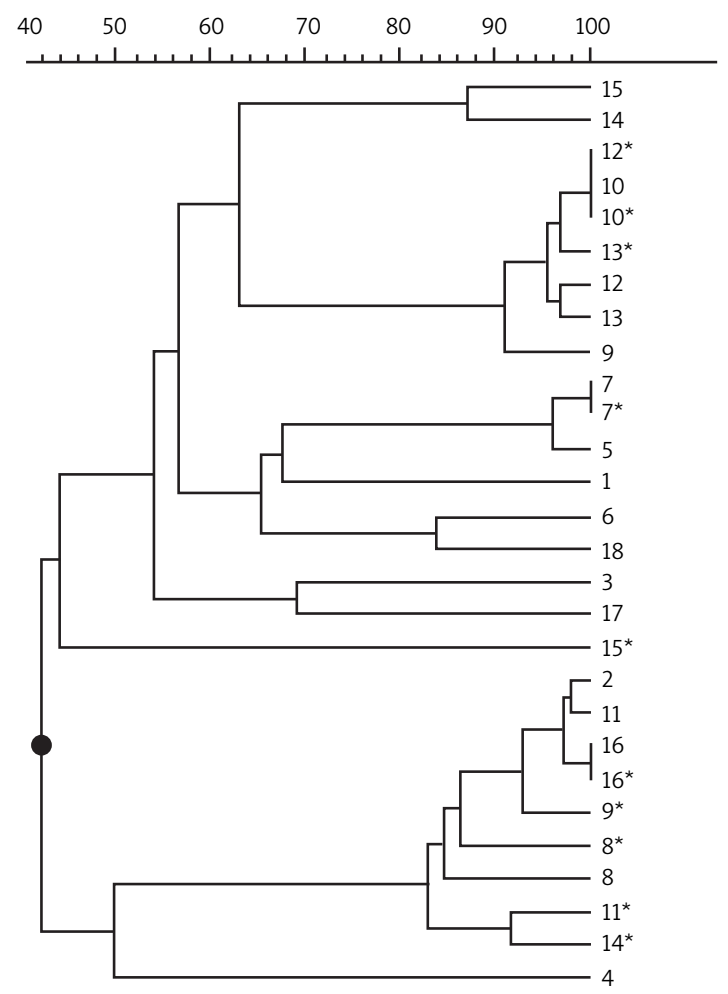

Figure 2. Dendrogram of the K. pneumoniae strains 
Table II. Antimicrobial and genetic patterns of $K$. pneumoniae ESBL-positive strains $(n=15)$

\begin{tabular}{|c|c|c|c|c|c|c|c|}
\hline \multirow{2}{*}{$\begin{array}{l}\text { Strain } \\
\text { number }\end{array}$} & \multirow{2}{*}{$\begin{array}{l}\text { Genetic } \\
\text { pattern }\end{array}$} & \multirow{2}{*}{$\begin{array}{c}\text { Susceptibility } \\
\text { pattern }\end{array}$} & \multirow{2}{*}{$\begin{array}{c}\text { Data } \\
\text { of isolation }\end{array}$} & \multicolumn{4}{|c|}{ MIC value $[\mathrm{mg} / \mathrm{l}]$} \\
\hline & & & & Imipenem & Gentamicin & Tigecycline & Ciprofloxacin \\
\hline 1 & $\mathrm{D}$ & c & $x 2006$ & 0.25 & 0.125 & 4 & 0.125 \\
\hline 2 & B & $f$ & XII 2006 & 0.75 & 8 & 1.5 & 64 \\
\hline 3 & D & $f$ & $x 2006$ & 0.125 & 8 & 2 & 64 \\
\hline 7 & C & a & IX 2006 & 0.19 & 0.25 & 0.047 & 0.125 \\
\hline $7^{*}$ & $C$ & a & X 2006 & 0.19 & 0.5 & 0.047 & 0.5 \\
\hline 8 & $\mathrm{D}$ & $\mathrm{d}$ & IX 2006 & 0.19 & 0.25 & 1 & 2 \\
\hline $8^{*}$ & $\mathrm{D}$ & $d$ & IX 2006 & 1 & 1 & 1 & 2 \\
\hline 9 & $A$ & e & IX 2006 & 0.75 & 2 & 8 & 4 \\
\hline $9^{*}$ & B & e & IX 2006 & 0.75 & 2 & 8 & 4 \\
\hline 10 & $A$ & $b$ & $x 2006$ & 0.19 & 32 & 1 & 0.5 \\
\hline $10^{*}$ & A & $b$ & X 2006 & 0.19 & 64 & 1 & 0.5 \\
\hline 11 & $B$ & $\mathrm{~d}$ & IX 2006 & 0.125 & 0.5 & 0.5 & 16 \\
\hline $11^{*}$ & $B$ & $\mathrm{~d}$ & $\times 2006$ & 0.125 & 1 & 0.5 & 64 \\
\hline 17 & $\mathrm{D}$ & $\mathrm{d}$ & X 2006 & 0.19 & 2 & 0.5 & 8 \\
\hline 18 & $A$ & $d$ & IX 2006 & 0.19 & 2 & 1 & 16 \\
\hline
\end{tabular}

Strains marked with the same numbers came from one child. Strains marked * were isolated from infections

Table III. Antimicrobial and genetic patterns of K. pneumoniae ESBL-positive strains $(n=13)$

\begin{tabular}{|c|c|c|c|c|c|c|c|}
\hline \multirow{2}{*}{$\begin{array}{l}\text { Strain } \\
\text { number }\end{array}$} & \multirow{2}{*}{$\begin{array}{l}\text { Genetic } \\
\text { pattern }\end{array}$} & \multirow{2}{*}{$\begin{array}{l}\text { Susceptibility } \\
\text { pattern }\end{array}$} & \multirow{2}{*}{$\begin{array}{c}\text { Data } \\
\text { of isolation }\end{array}$} & \multicolumn{4}{|c|}{ MIC value $[\mathrm{mg} / \mathrm{l}]$} \\
\hline & & & & Imipenem & Gentamicin & Tigecycline & Ciprofloxacin \\
\hline 4 & $\mathrm{D}$ & $d$ & X 2007 & 0.75 & 2 & 1 & 32 \\
\hline 5 & $\mathrm{D}$ & $d$ & $\times 2007$ & 0.38 & 0.125 & 0.25 & 4 \\
\hline 6 & $A$ & $\mathrm{~d}$ & $\times 2007$ & 0.38 & 0.125 & 0.5 & 4 \\
\hline 12 & $A$ & g & IX 2007 & 0.25 & 16 & 0.75 & 2 \\
\hline $12^{*}$ & $\mathrm{~B}$ & $g$ & $\times 2007$ & 0.25 & 32 & 0.75 & 2 \\
\hline 13 & $A$ & g & X 2007 & 0.19 & 256 & 1 & 4 \\
\hline $13^{*}$ & $A$ & g & X 2007 & 0.19 & 256 & 1 & 8 \\
\hline 14 & C & g & XI 2007 & 1 & 32 & 0.5 & 32 \\
\hline $14^{*}$ & $C$ & g & XI 2007 & 1 & 256 & 1 & 256 \\
\hline 15 & $\mathrm{D}$ & $f$ & XI 2007 & 0.19 & 8 & 1.5 & 32 \\
\hline $15^{\star}$ & $\mathrm{D}$ & $\mathrm{f}$ & XI 2007 & 0.19 & 16 & 2 & 32 \\
\hline 16 & $\mathrm{~B}$ & g & XI 2007 & 0.125 & 8 & 1 & 2 \\
\hline $16^{*}$ & B & g & XI 2007 & 0.125 & 16 & 1 & 4 \\
\hline
\end{tabular}

Strains marked with the same numbers came from one child. Strains marked * were isolated from infections

phage typing, and serological typing or drug sensitivity profiles. These methods, however, do not always provide a proper interpretation of an epidemiological situation. Molecular biology methods, including PFGE, allow for genetic differentiation of strains belonging to the same species. They are not commonly used in laboratories due to the lack of equipment and insufficient staff training. The studies of Demirdag and Hosoglu [2], Dzierżanowska et al. [3] and Ktari et al. [11] prove the use- fulness of both methods applied in this study for K. pneumoniae strain typing. Seven drug sensitivity profiles were determined among $28 \mathrm{~K}$. pneumoniae strains in this study. On this basis it can be assumed that certain K. pneumoniae strains survive in the clinic environment in which colonised patients or patients infected with these bacilli stayed. Strain typing on the basis of the drug sensitivity profile was one of the most frequently used methods in hospital strains. The introduction 
of genetic methods provided new opportunities within their typing and similarity determination. The results of PFGE chromosomal DNA isolation obtained in the study prove that during 15 months genetically identical $K$. pneumoniae strains were isolated from different children, in the case of both colonisation and infection. This may prove maintenance of colonization and dissemination of strains in children treated in the clinic involved in the study. From the results it was deduced that strains classified in the same group on the grounds of chromosomal DNA patterns can have different drug sensitivity profiles. Similar results were obtained by Bagattini et al. [12] when studying K. pneumoniae ESBL-positive strains isolated from children treated in the neonatal intensive care unit. No direct correlation was found between PFGE profiles and antibiotic susceptibility patterns. Isolates with identical antibiotypes belonged to different PFGE types. The various drug sensitivity profiles obtained for genetically identical K. pneumoniae strains may result from development of plasmid-encoded resistance genes. Non-compliance of a sanitary regime in the department as well as patients' migration within departments may affect development of drug sensitivity resistance genes through clinic strains. Equally significant is the ability of strains with different resistance mechanisms to survive in the hospital environment. Differences in MIC values for antibiotics of $K$. pneumoniae strains isolated from the same patient may suggest that survival of strains in a human body facilitates development of drug resistance during antibiotic therapy.

In conclusion, the results of the study suggest that establishing strains' similarity in epidemiological investigations should be based on results obtained by several methods, and that each phenotyping method should be complemented with genetic research.

\section{Acknowledgments}

This research was financially supported by the Nicolaus Copernicus University with funds from the maintenance of the research potential of the Department of Microbiology.

\section{References}

1. Empel J, Baraniak A, Literacka E, et al. Molecular survey of beta-lactamases conferring resistance to newer betalactams in Enterobacteriaceae isolates from Polish hospitals. Antimicrob Agents Chemother 2008; 52: 2449-54.

2. Demirdag K, Hosoglu S. Epidemiology and risk factors for ESBL-producing Klebsiella pneumoniae: a case control study. J Infect Dev Ctries 2010; 4: 717-22.

3. Dzierżanowska D, Kamińska W, Semczuk K, et al. Carriage of genes for various extended-spectrum $\beta$-lactamases: a novel resistance strategy of Klebsiella pneumoniae in Poland. J Ant Agents 2010; 35: 392-5.
4. Kwan SK, Lee JY, Baek JY, et al. Predominance of an ST11 extended-spectrum beta-lactamase-producing Klebsiella pneumoniae clone causing bacteriemia and urinary tract infections in Korea. J Med Microbiol 2010; 59: 822-8.

5. Vranic-Ladavec M, Bosnjak Z, Beader N, et al. Clonal spread of CTX-15-producing Klebsiella pneumoniae in a Croatian hospital. J Med Microbiol 2010; 59: 1069-78.

6. Conte MP, Venditti M, Chiarini F, et al. Extended spectrum beta-lactamase-producing Klebsiella pneumoniae outbreaks during a third generation cephalosporin restriction policy. J Chemother 2005; 17: 66-73.

7. Vimont S, Mnif B, Fevre C, Brisse S. Comparison of PFGE and multilocus sequence typing for analysis of Klebsiella pneumoniae isolates. J Med Microbiol 2008; 57: 1308-10.

8. Christian N, Roye-Green K, Smikle M. Molecular epidemiology of multidrug resistant extended spectrum betalactamase producing Klebsiella pneumoniae at a Jamaican hospital, 2000-2004. BMC Microbiol 2010; 10:27

9. www.korld.edu.pl/pdf/eucast/EUCAST_breakpoints_13popr.pdf

10. Tenover FC, Arbeit RD, Goering RV, Mickelsen PA, Persing $\mathrm{DH}$, Swaminathan B. Interpreting chromosomal DNA restriction patterns produced by pulsed-field gel electrophoresis: criteria for bacterial strain typing. J Clin Microbiol 1995; 33: 2233-9.

11. Ktari S, Arlet G, Mnif B, et al. Emergence of multidrug-resistant Klebsiella pneumoniae isolates producing VIM-4 metallo-beta-lactamase, CTX-M-15 extended-spectrumbeta-lactamase, and CMY-4 AmpC beta-lactamase in a Tunisian University Hospital. Antimicrobial Agents Chemother 2006; 50: 4198-201.

12. Bagattini M, Crivaro V, Di Popolo A, et al. Molecular epidemiology of extended-spectrum-beta-lactamaseproducing Klebsiella pneumoniae in a neonatal intensive care unit. J Antimicrob Chemother 2006; 57: 979-82. 